\title{
$\alpha$-Tropomyosin mutually exclusive exon selection: competition between branchpoint/polypyrimidine tracts determines default exon choice
}

\author{
Mary P. Mullen, Christopher W.J. Smith, James G. Patton, and Bernardo Nadal-Ginard \\ Laboratory of Molecular and Cellular Cardiology, Howard Hughes Medical Institute, Department of Cardiology, Children's \\ Hospital, Departments of Pediatrics and Cellular and Molecular Physiology, Harvard Medical School, Boston, Massachusetts \\ 02115 USA
}

We have used exons 2 and 3 of the rat $\alpha$-tropomyosin gene to analyze the basis of mutually exclusive exon selection. The basis of the strict mutually exclusive behavior of this exon pair is enforced by the proximity of the exon 3 branchpoint to the 5' splice site of exon 2 . With the exception of smooth muscle cells, exon 3 rather than exon 2 is incorporated into mRNA in all cell types. We show here, using both in vivo and in vitro cell-free systems, that this alternative exon selection is a consequence of general principles that govern $3^{\prime}$ splice site selection. In the absence of exon 3 , exon 2 is utilized efficiently in all cells. Selection of exon 3 is therefore the default result of a competition between exons 2 and 3 for the flanking constitutive splice sites. The basis of this competition is the relative strength of the polypyrimidine tract/branchpoint elements of the two exons. The major determinant of this splice site strength is the pyrimidine content adjacent to the branchpoint, and this involves no other sequence specificity. The branchpoint elements play an important but secondary role. The functional strengths of the different polypyrimidine tract/branchpoint combinations, as determined in cis competition assays, showed a perfect correlation with their binding affinities to a spliceosome component that interacts with the pre-mRNA in an ATP-independent manner. Selection of exon 3 in most cell types therefore reflects the preferential interaction of these splice site elements with constitutive splicing factors early in spliceosome assembly. The aspects of splice site selection analyzed here are likely to be of general applicability to constitutive and alternative pre-mRNA splicing.

[Key Words: Rat $\alpha$-tropomyosin gene; exon selection; branchpoint polypyrimidine tracts; splice site selection] Received December 10, 1990; revised version accepted February 1, 1991.

One of the major unresolved issues concerning premRNA splicing is the problem of splice site selection. Most eukaryotic genes possess multiple intervening sequences, or introns, each bounded by a pair of functional $5^{\prime}$ and $3^{\prime}$ splice sites. The open reading frame of the mature mRNA is preserved by the accurate excision of these introns from the primary transcript. Potentially, splice sites could pair in many different combinations disruptive to message integrity. That this does not occur to any great extent is testimony to the high fidelity of the splicing process. The role of limited consensus sequences at the ends of introns in specifying splice sites has long been recognized (Mount 1982). These elements include the practically invariant $\mathrm{GU}$ and $\mathrm{AG}$ dinucleotides at the $5^{\prime}$ and $3^{\prime}$ splice sites, respectively, the $5^{\prime}$ splice site consensus sequence that base-pairs with $U 1$ snRNA (Zhuang and Weiner 1986), the branchpoint consensus sequence that base-pairs with U2 snRNA (Parker et al. 1987; Wu and Manley 1989; Zhuang and Weiner 1989), and the polypyrimidine tract between the branch- point and the $3^{\prime}$ splice site AG. However, comparisons of primary sequences have yet to produce a set of rules with sufficient predictive value to rigorously identify authentic splice sites. Many genes contain sequences that closely resemble consensus elements but are not recognized as splice sites, except in certain instances upon mutation of the genuine sites or placement in altered sequence context (Treisman et al. 1983). Correct splice site selection in constitutively spliced genes involves an apparent paradox: Although all adjacent splice sites must be accurately recognized, all cryptic sites must be bypassed, even when they conform more closely to the consensus than the authentic sites (Ohshima and Gotoh 1987).

Various modes of alternative pre-mRNA splicing generate structurally and functionally distinct protein isoforms from individual genes, often in a tissue-specific or developmentally regulated manner, or both (for reviews, see Smith et al. 1989a; McKeown 1990). In alternatively spliced transcripts the problem of splice site selection is 
compounded by the fact that splice sites that are efficiently used in one cell type may be completely overlooked by the splicing machinery in other cells. Therefore, regulated alternative pre-mRNA processing must involve either differences in the constitutive cis- and trans-acting splicing elements or additional specific elements. Among the cis elements shown to influence alternative splice site selection are the relative homology to the consensus sequences for the $5^{\prime}$ splice site (Eperon et al. 1986; Zhuang et al. 1987) and the branchpoint (Reed and Maniatis 1988; Zhuang et al. 1989), the relative proximity of these elements (Fu et al. 1988a; Smith and Nadal-Ginard 1989|, the nature of the polypyrimidine tract (Fu et al. 1988b), the sequences between the 3' splice site and the branchpoint/polypyrimidine tract (Emeson et al. 1989; Goux-Pelletan et al. 1990; Helfman et al. 1990), the exon sequences (Reed and Maniatis 1986; Mardon et al. 1987; Streuli and Saito 1989), and the secondary structure (Solnick 1985; Libri et al. 1990). Much less is known about the trans factors that regulate alternative splicing. A number of Drosophila proteins, however, regulate splicing in an inhibitory manner (Za- char et al. 1987; Sosnowski et al. 1989; Siebel and Rio 1990) while the general splicing factor ASF/SF2 differentially activates certain $5^{\prime}$ splice sites in a concentrationdependent manner (Ge and Manley 1990; Krainer et al. 1990).

The rat $\alpha$-tropomyosin ( $\alpha \mathrm{TM}$ ) gene has proved to be a productive model system for the investigation of alternative splice site selection. This gene gives rise to at least 10 cell-specific protein isoforms through alternative splicing of three groups of exons (Wieczorek et al. 1988; Lees-Miller et al. 1990). At the $5^{\prime}$ end of the gene, exons 2 and 3 are spliced in a strict mutually exclusive fashion (Fig. 1). Exon 3 is incorporated predominantly in most cells, representing an apparent "default" selection by the splicing machinery, with the exception of smooth muscle where it is replaced by exon 2 (Wieczorek et al. 1988). Exons 2 and 3 are never spliced together. The basis of the strict mutually exclusive behavior in this system has been explained by the abnormally positioned upstream branchpoint of exon 3 (Smith and Nadal-Ginard 1989|. The proximity of this branchpoint to the $5^{\prime}$ splice site of exon 2 (41 nucleotides; Fig. 1) sterically inhibits
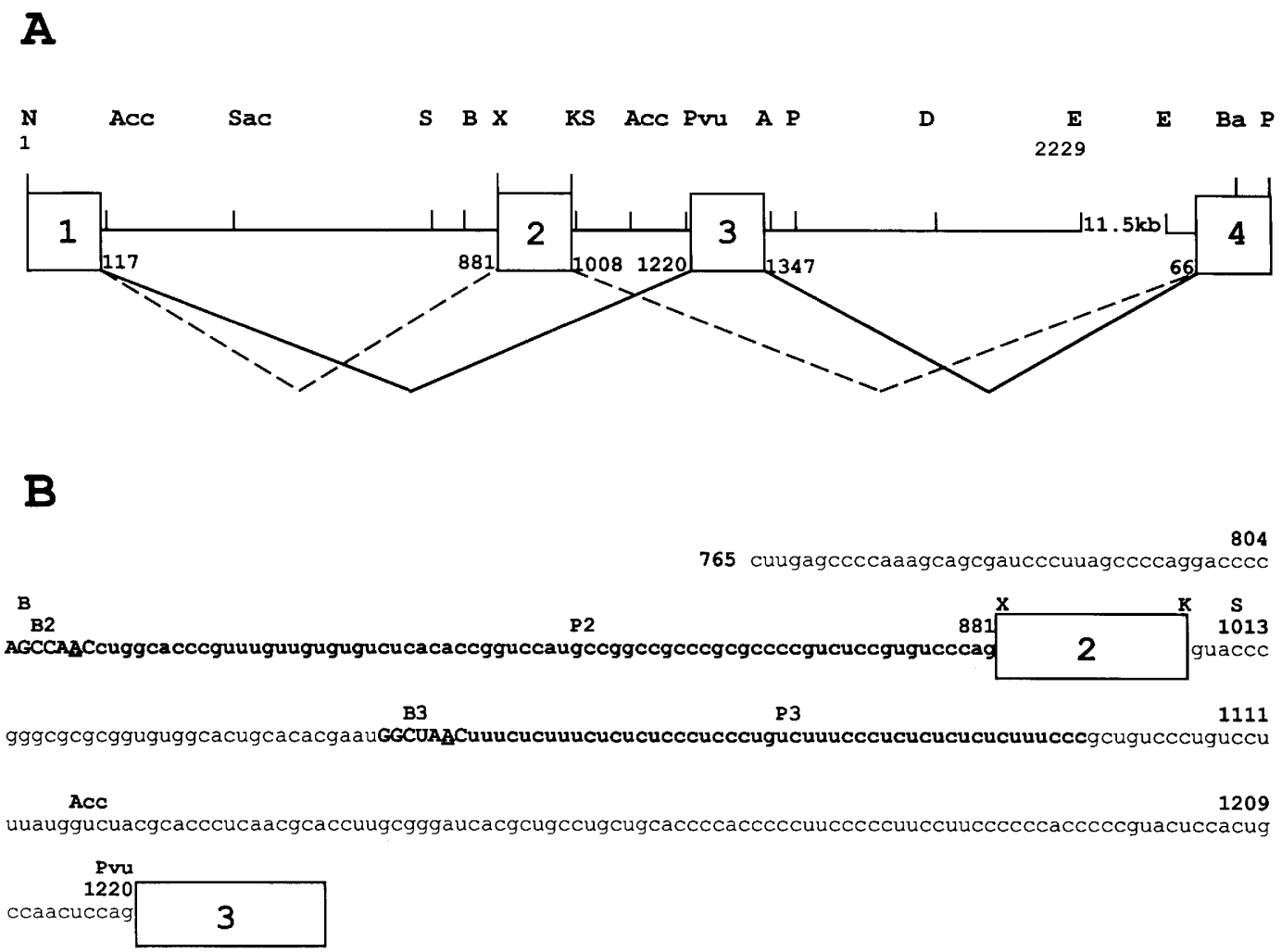

Figure 1. Mutually exclusive splicing of $\alpha$ TM exons 2 and 3. (A) Restriction map of exons $1-4$, with exons represented as boxes and introns depicted as horizontal lines. Default splicing pattern is indicated with solid diagonals representing the major splicing pathway; the alternative splicing pathway represented by dashed diagonal lines is predominant only in smooth muscle cells. Numbering is from the first nucleotide of the $\mathrm{NcoI}$ site that encompasses the initiation codon in exon 1 . The initial and terminal nucleotides of each intron are numbered. Restriction sites are designated as follows: (N) NcoI; (Acc) AccI; (Sac) SacI; (S) SmaI; (B) BgII; (X) XhoI; (K) KpnI; (Pvu) PvuII; (A) ApaLI; (P) PstI; (D) DraI; (E) EcoRI; (Ba) BalI. (B) The nucleotide sequences of the regions encompassing the branchpoints and polypyrimidine tracts of exons 2 and 3 . Branchpoint consensus sequences are shown as uppercase bold letters, with the branched nucleotide underlined. The sequences of the exon 2 and 3 polypyrimidine tracts (P2 and P3) are in lowercase bold letters. Restriction sites are as in $A$. 
the formation of an active spliceosome complex, thus preventing exons 2 and 3 from splicing together. This sets the stage for either the default selection of exon 3 or the regulated selection of exon 2 .

Here, we report on the determination of the selection of $\alpha \mathrm{TM}$ exon 3. Selection of exon 3 in most cell types is a truly default mechanism, representing the outcome of competition between exons 2 and 3 for the flanking constitutive splice sites. Default splice site selection requires limited specific sequences in the immediate vicinity of exons 2 and 3 and is determined by the competitive hierarchy between the branchpoint/polypyrimidine tract elements of exons 2 and 3 . Exon 3 is rendered more competitive primarily on the basis of its extensive polypyrimidine tract but also by its strong consensus branchpoint. These elements presumably provide strong binding sites for trans factors that act early in spliceosome formation. Indeed, we show by UV crosslinking that functionally stronger branchpoint/polypyrimidine tract elements bind more strongly to a specific spliceosome component.

\section{Results}

The default splicing pattern is established by competition between the mutually exclusive exons

To determine the minimal region of the $\alpha \mathrm{TM}$ gene required for correct default exon selection, constructs containing $\alpha \mathrm{TM}$ exons $1-4$ flanked by the SV40 early pro- moter and a functional poly(A) site were transfected into COS cells. The splicing pattern of transiently expressed cytoplasmic RNA was examined by $\mathrm{S} 1$ nuclease protection (Fig. 2). Constructs containing exons $1-4$ with intact introns (except for intron 3 , which is $>11 \mathrm{~kb}$ in the native gene), were spliced in the expected default pattern with incorporation of exon 3 in $>95 \%$ of the mRNA. The $\alpha \mathrm{TM}$ gene contains two other sets of exons that are alternatively spliced, and it is conceivable that prior selection in these regions could influence selection between exons 2 and 3 . This is not the case, however, as the same default selection of exon 3 was observed whether the sequences downstream of exon 4 were derived from SV40 (pSV1-4SV) or from smooth (pSVUT exons 4-6, 8-10, 13) or skeletal muscle-specific (pSVSK exons 4-6, 8-12) TM cDNA clones. Large deletions of the flanking introns 1 and 3 had little effect, except that some deletions within intron 3 gave a reduction in the already small proportion of transcripts containing exon 2 , leading to the exclusive use of exon 3 (pT1-4; C. Smith, unpubl.). Likewise, substitution of the flanking constitutive splice sites with heterologous sites had no effect on default selection of exon 3 (C. Smith, unpubl.). As expected from these data, deletion of exon 2 from these constructs also had no effect on inclusion of exon 3 (pTS3D). Thus, the information for default selection of exon 3 is contained within the immediate vicinity of exons 2 and 3.

The exclusion of exon 2, in transcripts from both the native gene and the transfected constructs, could be due

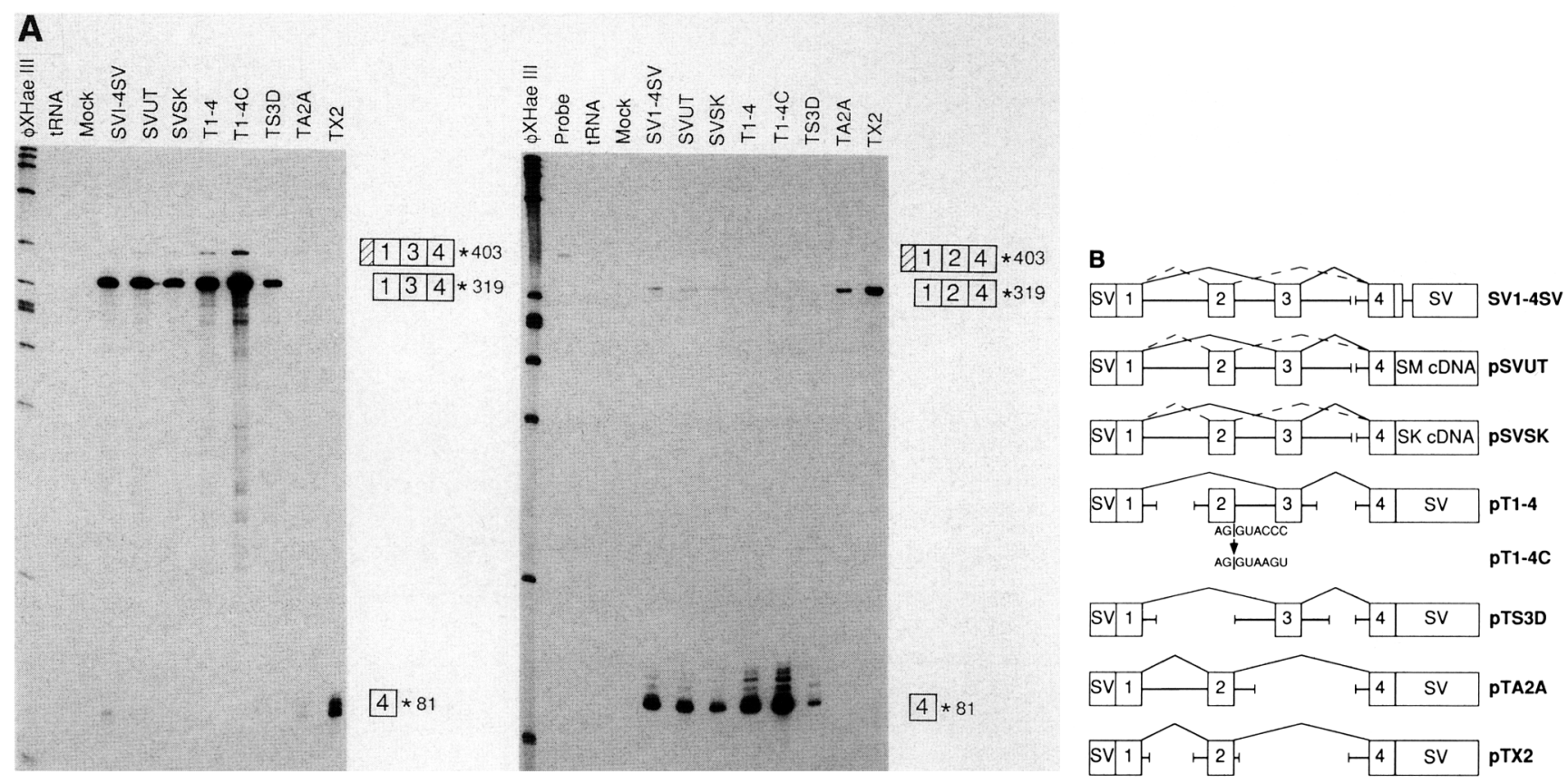

Figure 2. Default pattern selection is determined by competition between exons 2 and 3. (A) Cytoplasmic RNA from transiently transfected COS cells was analyzed by $\mathrm{S} 1$ nuclease analysis, using double-stranded cDNA-derived probes. Probes were 3'-end-labeled at a HindIII linker to distinguish construct-derived RNA from endogenous transcripts. $5^{\prime}$-Untranslated probe sequences allowed distinction between true full protection ( 319 nucleotides) and undigested probe ( 403 nucleotides). Partial protection for each probe was at 81 nucleotıdes. $(B)$ Diagrammatic representation of transfected constructs and summary of deduced splicing patterns. Open boxes represent exons; horizontal lines indicate introns. The derived splicing patterns are illustrated as the solid (predominant pathway) and dashed (minor pathway) diagonals at the top of each construct. 
to specific inactivation of exon 2 splice sites in cells that display the default pattern, or to competition by exon 3 . To distinguish between these possibilities we produced constructs pTA2A and pTX2 (Fig. 2), which contain exon 2 and varying amounts of flanking introns and in both of which exon 3 is deleted. RNA derived from these two constructs showed full incorporation of exon 2. Because exon 2 and its splice sites can be efficiently recognized by the splicing machinery of COS cells, the default exclusion of exon 2 must therefore be due to competition by exon 3 for the flanking splice sites. In this respect it seemed noteworthy that the $5^{\prime}$ splice site of exon 3 has a better match to the consensus AG GURAGU than does that of exon 2 (AT GUAAGU vs. AG GUACCC), which could potentially account for its preferential selection. The degree of conformity to the $5^{\prime}$ splice site consensus has been shown to affect splice site competition (Eperon et al. 1986; Zhuang et al. 1987). Moreover, this difference in match to the consensus is also conserved in the quail aTM gene (Lindquester et al. 1989). Mutating the 5' splice site of exon 2 in construct pT1-4 to the consensus in pT1-4C (Fig. 2), however, did not improve the competitive efficiency of exon 2 . Exon 3 was still selected exclusively, suggesting that default selection of exon 3 is not primarily the result of $5^{\prime}$ splice site competition.

\section{Default splicing is reproduced in a cell-free system}

Splicing to exon 3 has been shown previously to involve the use of a branchpoint within a strong consensus sequence 172 nucleotides upstream of exon 3 and to be dependent on an adjacent extensive ( $\sim 50$ nucleotides) polypyrimidine tract (Smith and Nadal-Ginard 1989; Smith et al. 1989b). To characterize the equivalent splice site elements associated with exon 2 and to investigate more thoroughly the factors responsible for the competition between exons 2 and 3, we turned to an analysis of pre-mRNA splicing by using an in vitro splicing system.

In vitro-synthesized ${ }^{32} \mathrm{P}$-labeled transcripts containing TM exons 1-3 were produced from DNA templates (pG4X1-4) linearized at the ApaLI site immediately downstream of exon 3 (see Fig. 1). These transcripts contained intact introns 1 and 2 and were potentially capable of either the 1-2 or the 1-3 splice but not the 2-3 splice, which remains sterically inhibited (Smith and Nadal-Ginard 1989). As shown in Figure 3A (left) incubation of these transcripts in a HeLa nuclear extract generated, in a time- and ATP-dependent manner, the expected products and intermediates of the default 1-3 splice. The identity of the lariats was verified by anomalous electrophoretic mobility and by debranching in HeLa cell S-100 fraction (Fig. 3A, middle). The branchpoint used in the 1-3 splice (Fig. 3A, right) was mapped to the same location 172 nucleotides upstream of the $3^{\prime}$ splice site, as previously characterized in single intron transcripts.

Transcripts containing exons 1 and 2 but lacking exon 3 (transcript 1-2), were produced from DNA templates linearized at the KpnI site immediately downstream of exon 2 (see Fig. 1). These transcripts were spliced efficiently to give the 1-2 spliced product and corresponding intermediates (Fig. 3B, left). This is in complete agreement with the above in vivo data (see Fig. 2), further demonstrating that competition between exons 2 and 3 for splicing to exon 1 establishes the default splicing pattern. Primer extension analysis (Fig. 3B, right) showed that the branchpoint used by exon 2 is an adenosine residue, 72 nucleotides upstream of exon 2 . The immediate sequence context of this branchpoint, AGCCAAC, does not match the consensus as well as that of exon 3 (Fig. $3 \mathrm{C}$ ), in that the -2 position relative to the branched nucleotide (underlined) is a $\mathrm{C}$, whereas the consensus $\mathrm{U}$ has been shown to improve competitive efficiency (Reed and Maniatis 1988). Inspection of the sequence between the branchpoint and the $3^{\prime}$ splice site revealed no obvious polypyrimidine tract; the longest unbroken stretch of pyrimidines is 5 nucleotides, with an overall pyrimidine content of $68 \%$, as compared with the $\sim 50$ nucleotide polypyrimidine tract of exon 3 (Fig. $3 \mathrm{C}$ ).

Competition between the branchpoint/polypyrimidine tracts of exons 2 and 3 establishes the default pattern

Because the exon 3 branchpoint and pyrimidine tract adhere more closely to the consensus for these elements than do those of exon 2, we postulated that competition between exons 2 and 3 might be due to the hierarchical strengths of the branchpoints and polypyrimidine tracts. To test this hypothesis we devised a series of constructs containing modular substitutions of these elements. In these substituted constructs the branchpoint elements associated with exons 2 and 3, referred to as B2 and B3, respectively, contain the heptanucleotide branchpoint sequence. In addition, when B2 was placed between exons 2 and 3 it was accompanied by sufficient upstream sequences to maintain the native 41 -nucleotide $5^{\prime}$ splice site-branchpoint separation that enforces mutually exclusive splicing. The substituted pyrimidine tract modules, referred to as $\mathrm{P} 2$ and $\mathrm{P} 3$, contain all sequences between the branchpoint sequence and the $3^{\prime}$ splice site AG.

In the first substituted pre-mRNA, the exon 2 branchpoint/polypyrimidine tract (B2P2) was replaced by a duplicated version of the equivalent exon 3 elements (B3P3) (transcript $1^{\mathrm{B3P} 3} 23$; Fig. 4, lanes 4-6). This replacement resulted in a switch in the splicing pattern from the default 1-3 splice of transcript 123 to a very efficient $1-2$ splice. This result demonstrates that the exon 3 branchpoint/pyrimidine tract elements are not only closer to consensus but are also functionally stronger than those of exon 2 and confirms previous observations that in cis competition between equivalent splice sites, the proximal site is selected (Reed and Maniatis 1986). In the complementary substitution, replacement of B3P3 by a duplicated B2P2, the same switch in splicing pattern from 1-3 to 1-2 splicing was observed (Fig. 4A, transcript $12^{\mathrm{B} 2 \mathrm{P} 2} 3$, lanes $7-9$, again confirming the $\mathrm{B} 3 \mathrm{P} 3>\mathrm{B} 2 \mathrm{P} 2$ hierarchy. As expected, interchanging B2P2 with B3P3 


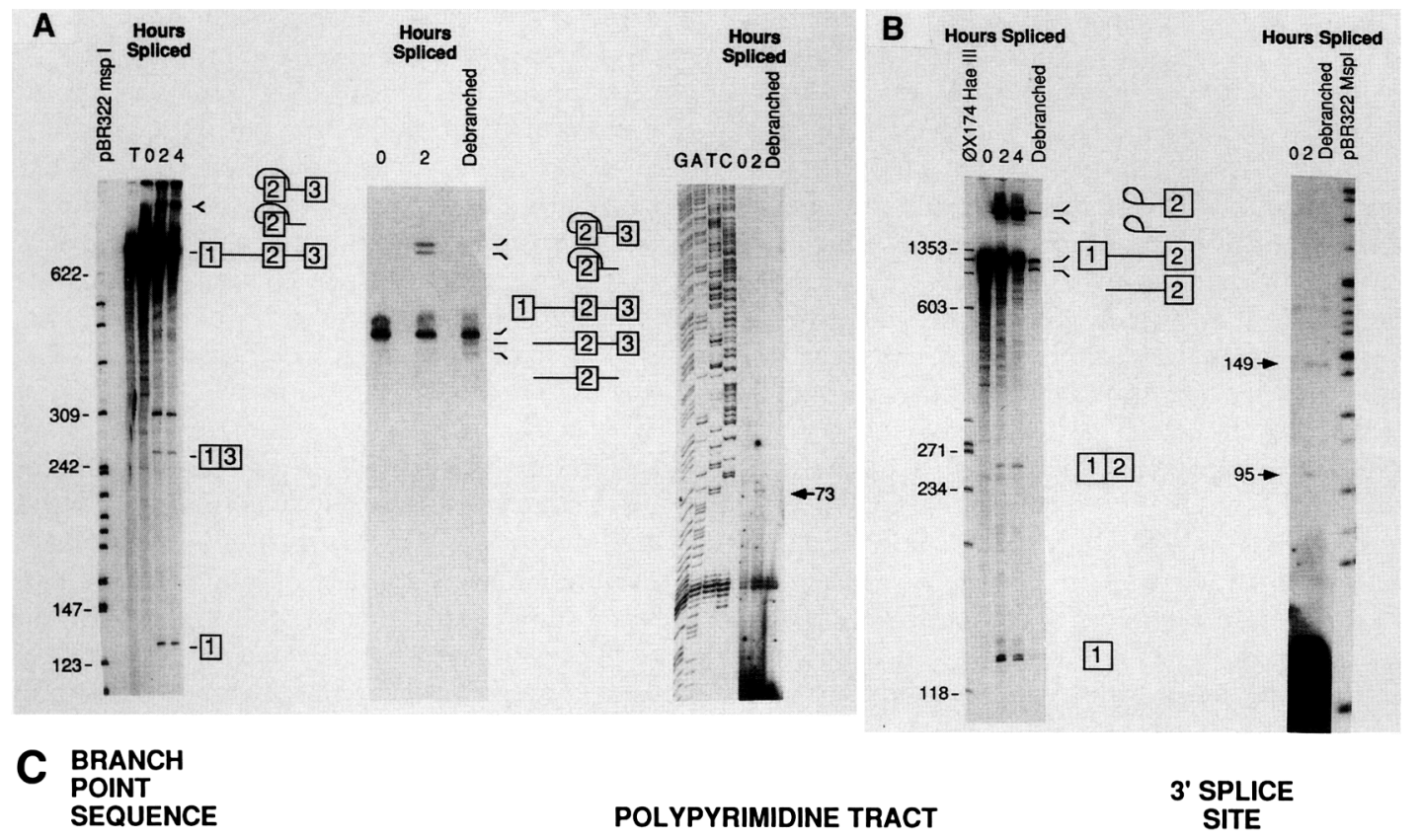

YNYURAY

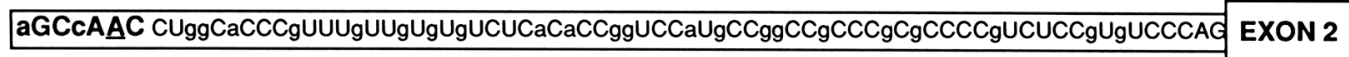

gGCUAACUUUCUCUUUCUCUCUCCCUCCCUgUCUUUCCCUCUCUCUCUCUUUCCCgCUgUCCCUg -107nt-CAG EXON 3

Figure 3. Default splicing of tropomyosin exons 1-3 is reproduced in vitro and displays competition between exons 2 and 3 . $(A)$ ${ }^{32}$ P-Labeled pre-mRNA transcript 123 containing exons 1-3 was generated with T7 polymerase from the APAL1-truncated DNA template pG4X1-4. (Left) RNA was incubated in HeLa cell nuclear extract under standard splicing conditions for times shown and electrophoresed on a $4 \%$ denaturing gel next to unprocessed transcript $(\mathrm{T})$. Transcript, reaction intermediates and products are schematically indicated at right. Sizes of initial transcript, 5' exon, and 1-3 spliced product were 1360, 125, and 250 nucleotides, respectively. Band at 309 nucleotides is a product of exonuclease protection resulting from protection against the action of an exonuclease in the extract by factors binding at B3. It is composed of a protected region extending $3^{\prime}$ from exon 3 to the exon 3 branchpoint and is reprodicibly present in reactions involving the transcript 123. (Middle) RNA was incubated in splicing reaction for 0 or $2 \mathrm{hr}$ and run directly on a $4 \%$ denaturing gel or debranched in HeLa cell S-100 fraction for 30 min under standard conditions (Ruskin and Green 1985). Transcripts, lariats, and debranched lariats are shown schematically at right. The sizes of the debranched intermediate and product lariats were 1116 and 991 nucleotides, respectively. (Right) The branchpoint utilized in the 1-3 splice was mapped by primer extension of an in vitro splicing reaction. Transcript 123 was incubated in an in vitro slicing reaction for 0 or $2 \mathrm{hr}$ and then hybridized directly or after debranching to a $5^{\prime 32}$-labeled oligomer complementary to nucleotides $1095-1122$ within intron 2 (Smith and Nadal-Ginard 1989). Primer extension was performed with AMV reverse transcriptase, and products were analyzed on a 6\% denaturing gel next to a DNA sequencing reaction. The designated band of 73 nucleotides was produced by extension to the branchpoint. $(B, \text { left })^{32} \mathrm{P}$-Labeled T7 transcripts containing exons 1 and 2 were produced from pGX1-4 truncated after exon 2 with $A s p$ 718. In vitro splicing and debranching reactions were performed at times indicated, and reaction products (right) were analyzed on a $4 \%$ denaturing gel. The sizes of the various RNA species were primary transcript, 1016 nucleotides, $5^{\prime}$ exon, 125 nucleotides; debranched lariat intermediate, 891 nucleotides; 1-2 spliced product, 250 nucleotides. (Right). The branchpoint used in the 1-2 splice was mapped by primer extension to 72 nucleotides $5^{\prime}$ of exon 2 . In vitro splicing was carried out for times indicated, and primer extension was performed, either directly or after debranching, with a ${ }^{32} \mathrm{P}$-labeled primer hybridizing to the first 24 nucleotides of exon 2. Bands shown indicate extension to the branchpoint ( 95 nucleotides) or the end of spliced product (149 nucleotides). Primer extension shown here results from hybridization to splicing reaction of transcript $12^{\mathrm{B} 2 \mathrm{P} 2} 3$ (see Fig. 4); primer extension of splicing reaction from transcript 1-2 gives identical results. Identity of this branchpoint was also confirmed by electrophoresis alongside a sequencing ladder on a high-resolution gel. $(C)$ Comparison of the exon 2 and exon 3 branchpoint/polypyrimidine tract sequences indicates basis for competition.

also resulted in a $1-2$ splice (Fig. 4A, transcript $1^{\mathrm{B} 3 \mathrm{P}_{3}} 2^{\mathrm{B} 2 \mathrm{P2}} 3$, lanes $\left.10-12\right)$. Taken together, these in vitro data indicate that the splicing pattern in the default en- vironment is determined by cis-regulated competition between the branchpoint/polypyrimidine tract elements of exons 2 and 3. 


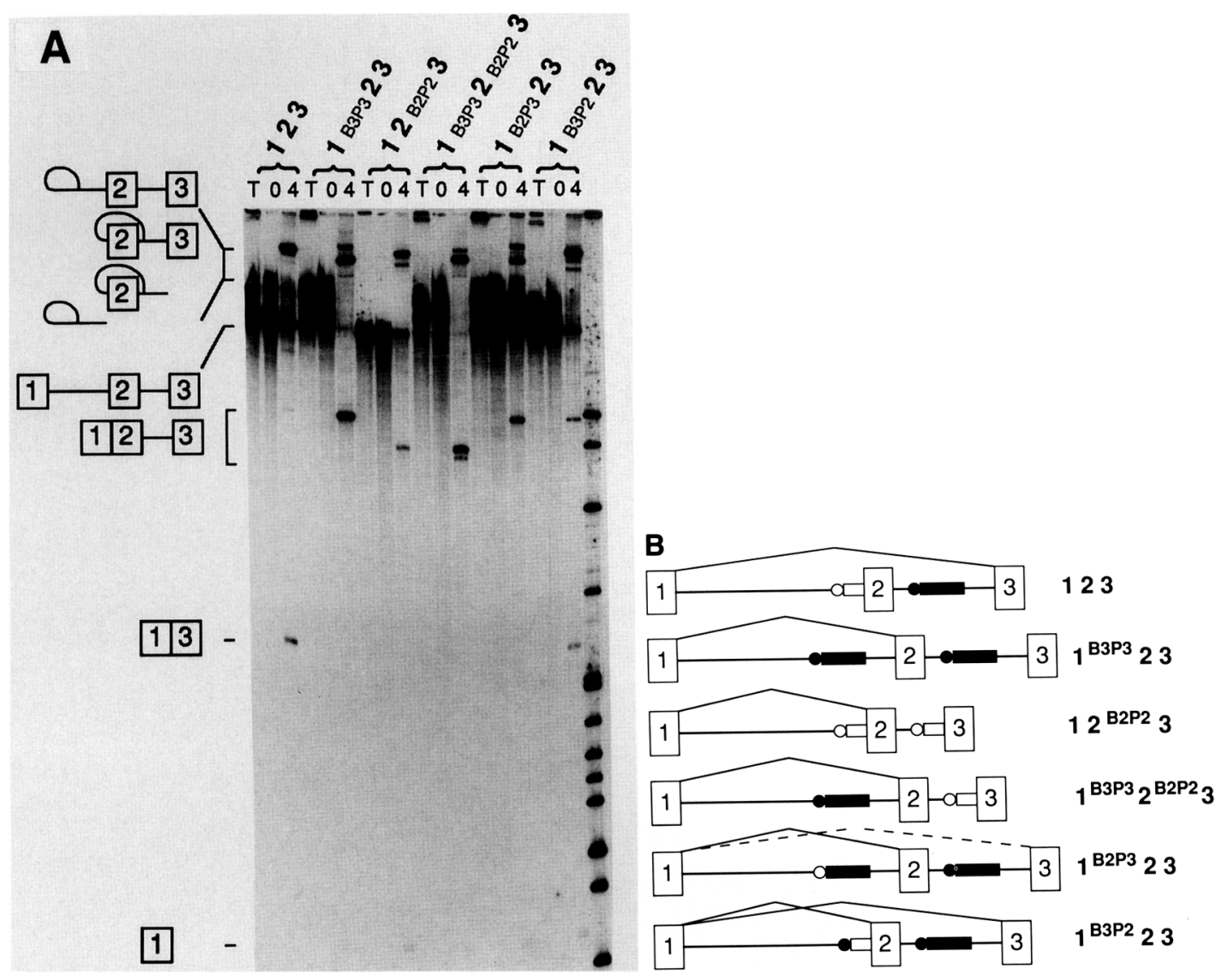

Figure 4. The default pattern is specified by the relative strengths of branchpoints and polypyrimidine tracts. $(A) \mathrm{T} 7$ transcripts labeled with ${ }^{32} \mathrm{P}$ were generated from substituted TM 123 ApaL1-cleaved DNA templates, incubated in HeLa nuclear extract under standard splicing conditions for the times shown $(0,4 \mathrm{hr})$, and run on a $4 \%$ denaturing gel. Transcripts $(\mathrm{T})$, reaction intermediates, and products are depicted at left. In all substituted constructs, exons 2 and 3 were precluded from splicing together owing to preservation of the 41-nucleotide spacing of the exon 3 branchpoint from exon 2 donor site (see text). Sizes of spliced products were transcript 123, 250-nucleotide 1-3 splice; transcript $1^{\mathrm{B} 3 \mathrm{P} 3} 23$, 594-nucleotide 1-2 splice; transcript $12^{\mathrm{B} 2 \mathrm{P} 2} 3,481$-nucleotide $1-2$ splice; transcript $1^{\mathrm{B} 3 \mathrm{P} 3} 2^{\mathrm{B} 2 \mathrm{P} 2} 3$, 481-nucleotide 1-2 splice; transcript $1^{\mathrm{B} 2 \mathrm{P} 3} 23$, 594-nucleotide 1-2 major splice; and 250-nucleotide minor 1-3 splice; and transcript $1^{\mathrm{B} 3 \mathrm{P}} 23,594$-nucleotide 1-2 splice and 250-nucleotide 1-3 splice. (B) Structures and splicing patterns of substituted transcripts are diagramed schematically. Exons are designated by numbered boxes; introns are shown as intervening lines. Branchpoints appear as circles; polypyrimidine tracts appear as rectangles. Branchpoints/polyprimidine tracts of exon 2 are depicted as open symbols; those of exon 3 are shown as solid symbols. The polypyrimidine tract of exon 3 (P3) was always substituted along with all other sequences, up to the $3^{\prime}$ splice site AG, represented by the solid line downstream of P3. Major and minor splicing patterns are represented by solid and dashed diagonal lines.

To further dissect the contributions of the branchpoint and the polypyrimidine tract in establishing the B3P3 $>$ B2P2 hierarchy, we analyzed the in vitro splicing pattern of constructs in which these elements were altered individually. Replacement of the polypyrimidine tract of exon 2 with that of exon 3 , leaving the branchpoint unchanged (Fig. 4A, transcript $1^{\mathrm{B} 2 \mathrm{P} 3} 23$, lanes 1315), produced efficient $1-2$ splicing with a small but detectable fraction of 1-3 splicing. On the other hand, changing only the exon 2 branchpoint to that of exon 3 (B3P2) led to a splicing pattern intermediate between that of the wild-type transcripts and those in which B3P3 or B2P3 had been placed in front of exon 2; both the 1-2 and 1-3 splices were observed (Fig. 4A, transcript $1^{\mathrm{B} 3 \mathrm{P} 2} 23$, lanes $16-18$ ). These data establish a hierarchy for the different branchpoint/polypyrimidine tract combinations: B3P3 $>$ B2P3 $>$ B3P2 $>$ B2P2. From these results it is clear that the relative strengths of the polypyrimidine tracts are the major determinants in specifying the default pattern, with the relative branchpoint strengths playing a secondary role.

In the transcripts in which the splicing pattern was changed by placing P3 in front of exon 2, the entire region between the branchpoint and 3' splice site of exon 3 was substituted. In addition to the functional polypyrimidine tract (nucleotides 1040-1087, Fig. 1), this region contains elements between the polypyrimidine tract and $3^{\prime}$ splice site (nucleotides 1087-1220). These sequences are not necessary for splicing and can be deleted without impairment of splicing efficiency. Neverthless, this re- 
gion does contain elements that are involved in the smooth muscle-specific suppression of exon 3 /C. Smith and B. Nadal-Ginard, unpubl.). To confirm that the switch in splicing patterns described above was due only to the substitution of a strong polypyrimidine tract and not to any other sequence elements, we replaced the sequences immediately downstream of B2 with an artificial "generic" tract of 36 uninterrupted pyrimidines. The remaining sequences between the new pyrimidine tract and the $3^{\prime}$ splice site were left unchanged, and the 72 nucleotide distance from the branchpoint to the $3^{\prime}$ splice site was conserved. This substitution caused a complete switch from $1-3$ to 1-2 splicing (Fig. 5, transcript $1^{\text {Pgen }} 23$, lanes 15-18). Taken together, these results emphasize the predominant role of a strong polypyrimidine tract in establishing the default splicing pattern and confirm that no additional sequence specificity is required within the polypyrimidine tract for this effect.

\section{Quantitative polyprimidine tract changes produce qualitative alterations in splicing pattern}

To assess the relative extent of polypyrimidine tract required for effective competition in establishing the de- fault splicing pattern, we examined a series of TM123 transcripts containing deletions of P3. Progressive deletions were made from the AccI site /nucleotide 1117; Fig. 1 ) into the $3^{\prime}$ end of the functional polypyrimidine tract. It has been shown previously that this tract can be deleted from $\sim 50$ nucleotides to 17 nucleotides without impairing splicing efficiency in single intron transcripts (Smith et al. 1989b), although further deletion to $9 \mathrm{nu}-$ cleotides does reduce splicing efficiency. No effect on the splicing pattern of TM123 transcripts was seen upon deletion of the polypyrimidine tract to 39 pyrimidines; the 1-3 splice was retained (Fig. 5 ; transcript $12^{\mathrm{P} 39} 3$, lanes 4-6). Deletions retaining 17,9, or 1 pyrimidines led to a complete switch in splicing pattern from $1-3$ to $1-2$ (transcripts $12^{\mathrm{P} 17} 3,12^{\mathrm{P9}} 3,12^{\mathrm{Pl}} 3$ ). These results confirm that the extensive exon 3 polypyrimidine tract is essential for effective competition with exon 2 . In comparing these data with the effects of the same deletions in a single intron context (Smith et al. 1989b), it is apparent that efficiency of splicing in a single intron does not correlate precisely with the ability to function in cis competition; although the 17 nucleotide polypyrimidine tract was outcompeted by $\mathrm{B} 2 \mathrm{P} 2$, in the absence of competition the same element showed a splicing efficiency
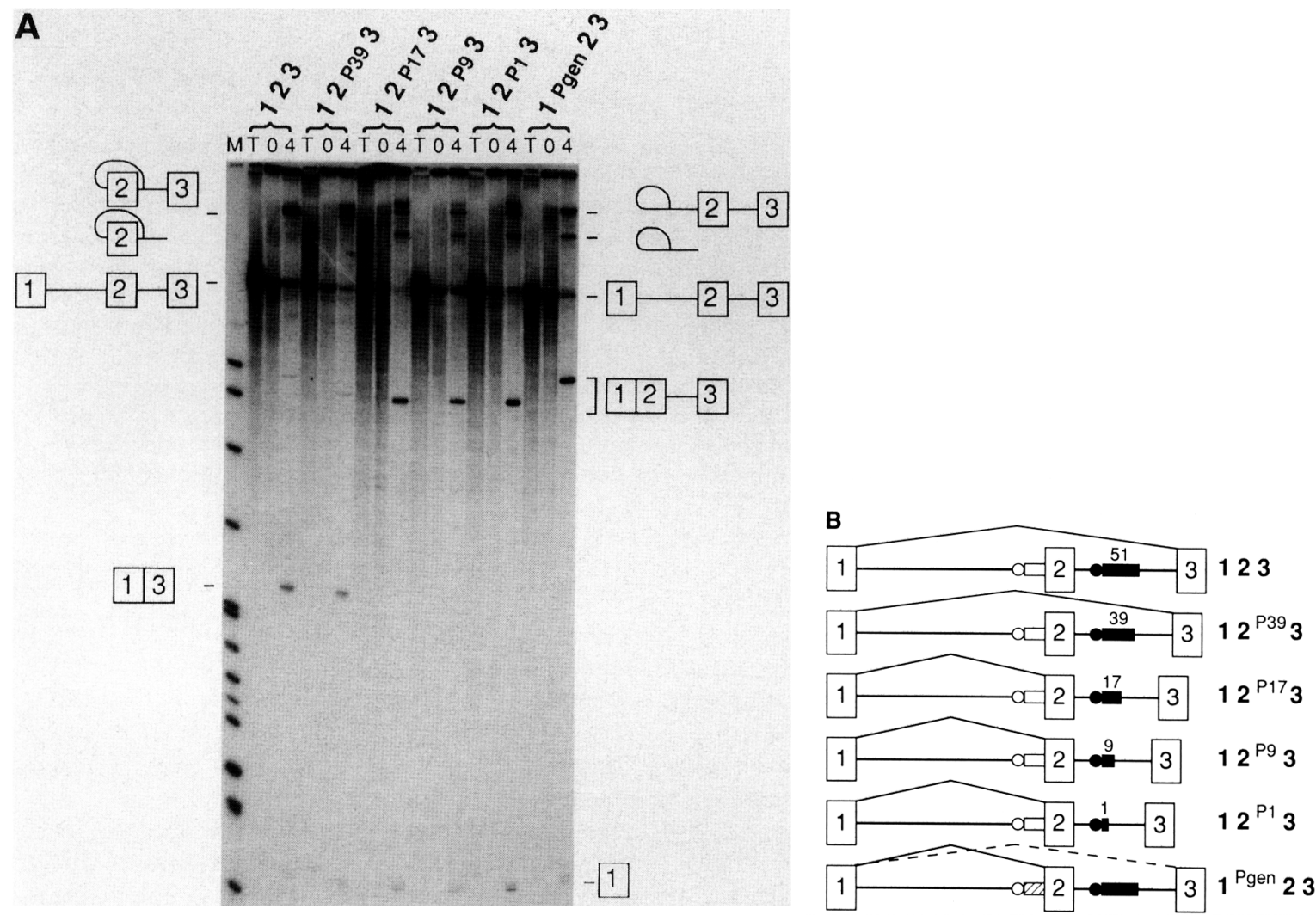

Figure 5. Progressive polypyrimidine tract deletions alter splicing pattern. (A) Pre-mRNAs labeled with ${ }^{32} \mathrm{P}$ were incubated in standard in vitro splicing reactions for times indicated $(0,4 \mathrm{hr})$ and run on a $4 \%$ denaturing gel. Sizes of spliced products were transcript 123, 250-nucleotide 1-3 splice; transcript $12^{\mathrm{p} 39} 3,250$-nucleotide 1-3 splice; transcript $12^{\mathrm{P} 17} 3$, 543-nucleotide 1-2 splice; transcript $12^{\mathrm{P9}} 3$, 535-nucleotide 1-2 splice; transcript $12^{\mathrm{P1}} 3$, 527-nucleotide 1-2 splice; and transcript $1^{\mathrm{Pgen}} 23$, 594-nucleotide 1-2 splice. (M) Marker lane; $(T)$ transcript. (B) Structures and splicing patterns of substituted transcripts are diagramed schematically. Pyrimidines remaining are designated above $\mathrm{P} 3$; generic polypyrimidine tract is shown as hatched rectangle. 
indistinguishable from the wild type (Smith et al $1989 \mathrm{~b}$ ). Thus, the nature of the polypyrimidine tract influences the efficiency of at least two steps in the splicing pathway; one involved in determination of splice site selection, and a later step that determines the overall rate of the splicing reaction. These data demonstrate that a relatively long polypyrimidine tract $(>17-39$ nucleotides) is required to establish default selection of exon 3 .

\section{Branchpoint/polypyrimidine tract competition controls exon selection in vivo}

The branchpoint/polypyrimidine tract competitions described above were analyzed in vitro in the absence of the downstream splice sites of exons 3 and 4 . In native transcripts there are also potential cis competitions between the 1-3 and 2-4 splicing events and between 2-4 and 3-4 splices. These competitions could potentially play a role in exon selection and complicate the interpretation of the preceding in vitro results. The lack of effect on converting the $5^{\prime}$ splice site of exon 2 to the consensus (Fig. 2), however, argues against a determining role in exon selection for these competitions. To confirm the primary role of the $1-2$ versus $1-3$ competition in default exon selection, we returned to the in vivo transfection system. The transfected constructs all contained exons $1-4$, with various substitutions of B2P2 by B3P3, $\mathrm{B} 2 \mathrm{P} 3$, or $\mathrm{B} 3 \mathrm{P} 2$. The structure of the resulting cytoplasmic mRNAs, as determined by $\mathrm{S} 1$ nuclease analysis, are shown in Figure 6 and are consistent with the in vitro data. Although the wild-type transcripts were spliced according to the default pattern (Fig. 6; SV1-4), the inclu- sion of exons $1-3-4$ predominating over $1-2-4$, all of the substitutions of $\mathrm{B} 2 \mathrm{P} 2$ resulted in a shift toward the 12-4 pathway (Fig. 6, lanes 6-8). Substitution of B3P3 or B2P3 resulted in almost exclusive 1-2-4 splicing $\left(\mathrm{SV}^{\mathrm{B} 3 \mathrm{P} 3} 234, \mathrm{SV}^{\mathrm{B} 3 \mathrm{P} 2} 234\right)$, whereas substitution of the branchpoint only (B3P2) had an intermediate pattern, with more 1-2-4 than wild type but with less 1-2-4 than the P3 substitutions (SV1 ${ }^{\mathrm{B} 3 \mathrm{P} 2}$ 234). Thus, both the determining role of the 1-2 versus 1-3 competition in default exon selection and the predominant influence of the relative polypyrimidine tract strengths in establishing the $\mathrm{B} 3 \mathrm{P} 3>\mathrm{B} 2 \mathrm{P} 2$ hierarchy, both in vivo and in vitro, are confirmed.

The functional hierarchy of branchpoint/polypyrimidine tract elements correlates with binding to a spliceosome component

The clear role played by the branchpoint/polypyrimidine tract elements in default exon selection suggests a differential interaction of these elements with trans-acting factors. In an attempt to identify these factor|s|, we have used UV cross-linking to RNA substrates containing the same $\alpha \mathrm{TM}$ branchpoint/polypyrimidine tract combinations used above. UV cross-linking allows transfer of labeled nucleotides to proteins that bind substrate RNAs in a proper configuration (Mayrand and Pederson 1990). We have detected a very efficiently cross-linked protein of $\sim 60 \mathrm{kD}$ that binds to the extensive polypyrimidine tract upstream of exon 3 (P3). Although care must be taken in interpreting UV cross-linking results, it appears that the cross-linking of this factor is specific because it
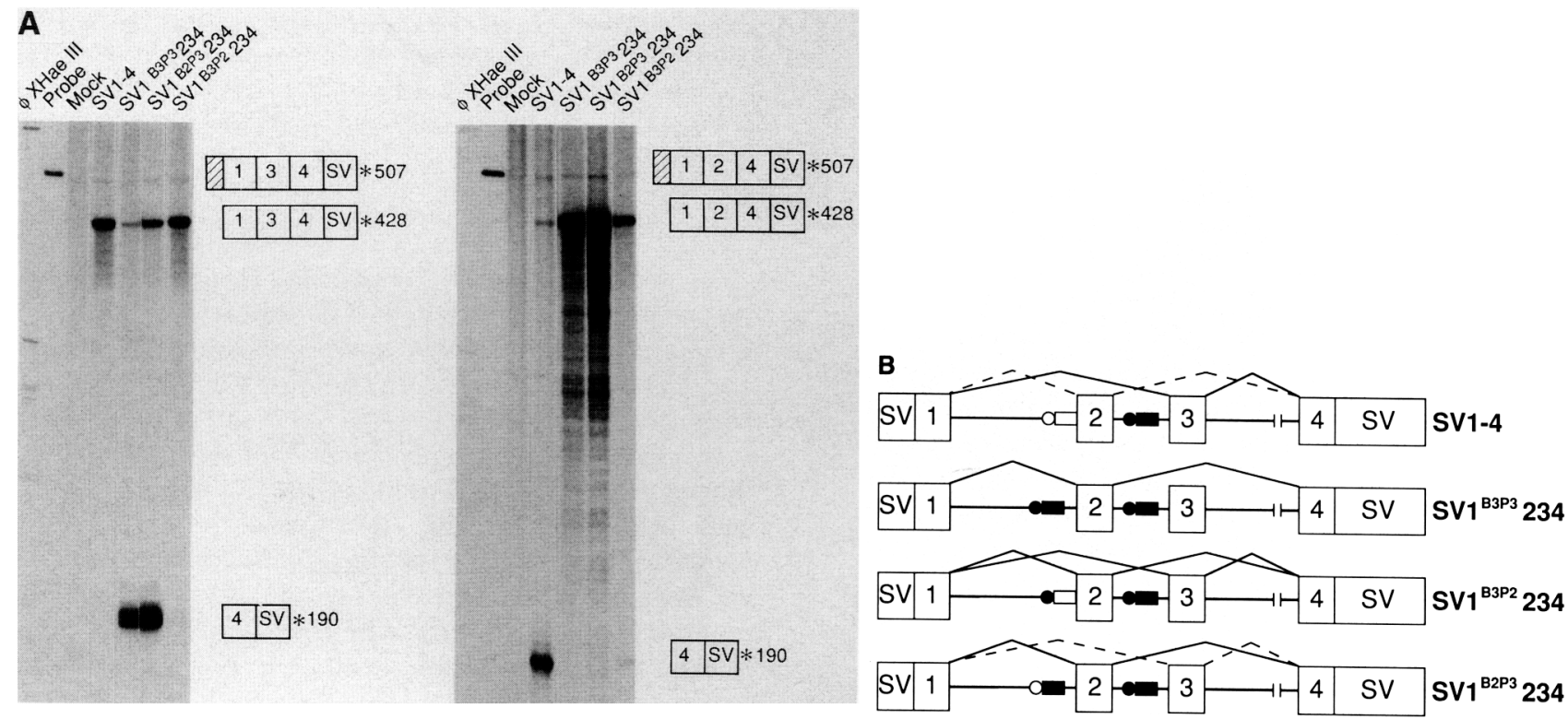

Figure 6. In vivo splicing of substituted constructs matches results from cell-free system; the default pattern is generated by competition between branchpoints and polypyrimidine tracts. (A) Cytoplasmic RNA from transiently transfected COS cells was analyzed by S1 nuclease analysis, using double-stranded PCR-generated probes. These were labeled at the $3^{\prime}$ end SV40 sequence to distinguish plasmid derived from endogenous TM transcripts. 5 '-Untranslated probe sequences allowed separation of full protection (428 nucleotides) and undigested probe (507 nucleotides). Partial protection was at 190 nucleotides. (B) Structures and deduced splicing patterns of transfected constructs are represented diagrammatically. Splicing patterns are shown as solid (major) and interrupted (minor) diagonals above each construct. 
can be competed by unlabeled self-competitor but not by nonspecific competing RNA (see below) and because only one major protein cross-links to the probes tested, arguing against a nonspecific artifact. In addition, this factor has been purified by using poly(U)-Sepharose (J.G. Patton and B. Nadal-Ginard, in prep.), again arguing that its interaction with the polypyrimidine tract is not an artifactual consequence of uridine hyperphotoreactivity. This protein, referred to in our laboratory as polypyrimidine-binding protein (PBP), displays several similar characteristics to a previously defined spliceosome component, PTB (Garcia-Blanco et al. 1989), and partial peptide analysis has shown that these proteins share at least one common peptide (J.G. Patton, unpubl.). It should be noted, however, that this protein is not related to U2AF, a $65-\mathrm{kD}$ polypyrimidine-binding protein that is necessary for U2 snRNP binding and for splicing (Zamore and Green 1990,1991).

$A$ variation of the complementation assay used to show that U2AF is necessary for splicing has also been used to show that PTB/PBP, purified according to GarciaBlanco et al. (1989), restores splicing activity to depleted extracts (J.G. Patton and B. Nadal-Ginard, in prep.). We therefore attempted to determine whether $\mathrm{PTB} / \mathrm{PBP}$ could differentially recognize the branchpoint/polypyrimidine tract combinations used above. To this end, we have used a competition assay where multiple branchpoint/polypyrimidine tract RNAs are competed against B3P3 RNA for the binding of PTB/PBP as detected by UV cross-linking (for sequences, see Materials and methods). This assay is dependent on relative affinities between protein and RNA and is not dependent on differences in cross-linking efficiency between the various RNAs. The data shown in Figure 7 demonstrate that B3P3 is clearly the best competitor followed by B2P3, followed by human $\beta$-globin intron 1 branchpoint/polypyrimidine tract. B3P2 is a less effective competitor, whereas B2P2 and a bacterial RNA (pGem) do not compete effectively, even at the highest molar excess used. Significantly, the order of competition of the sequences tested for binding to PTB/PBP is the same order that has been determined for these sequences using cis competition splicing as an assay: $\mathrm{B} 3 \mathrm{P} 3>\mathrm{B} 2 \mathrm{P} 3>\mathrm{B} 3 \mathrm{P} 2>\mathrm{B} 2 \mathrm{P} 2$. In addition, the binding of this factor also correlates with the splicing behavior of the polypyrimidine tract deletion mutants. Competition is reduced to barely detectable or undetectable when this tract is reduced from its native $\sim 50$-nucleotide length to 17 or 9 nucleotides, respectively. Thus, binding of PTB/PBP correlates exactly with splice site selection for both the branchpoint/polypyrimidine tract combinations and the polypyrimidine tract deletion constructs. This binding is due to both the branchpoint and the polypyrimidine tract (cf. B3P3 with B2P3), although deletions in the polypyrimidine tract by themselves can also abolish binding. A combinatorial effect between these elements likely creates a range of binding sites with an accompanying range of affinities for factor binding. These results agree with and extend the previously noted correlation between PTB cross-linking and the ability of various $3^{\prime}$ splice site/pyrimidine tract mu-

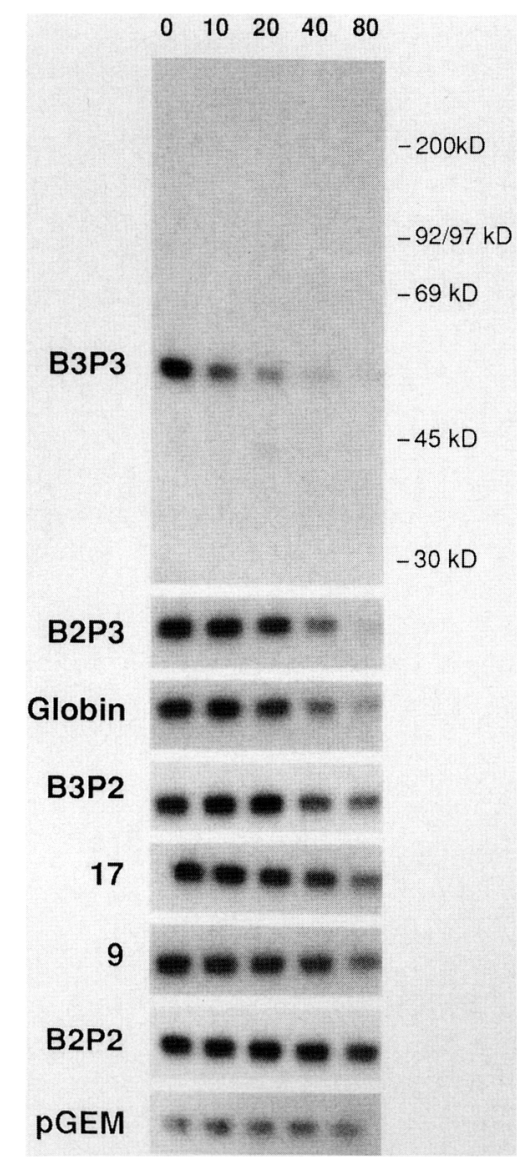

Figure 7. PTB/PBP binds more efficiently to functionally stronger branchpoint/polypyrimidine tracts. B3P3 RNA labeled with ${ }^{32} \mathrm{P}$ was incubated in nuclear extract with the indicated molar excess of unlabeled competitor RNA and UV cross-linked at $254 \mathrm{~nm}$. Labeled proteins were then separated on 9\% Laemmli gels. Markers were ${ }^{14} \mathrm{C}$-labeled proteins from New England Nuclear. The structure of the RNAs used are detailed in Materials and methods.

tants to form U2 snRNP-containing complexes (GarciaBlanco et al. 1989). Whether PTB/PBP is the only factor involved in determining $3^{\prime}$ splice site strength is not yet clear, as a number of proteins binding to this region have been identified (Gerke and Steitz 1986; Tazi et al. 1986; Ruskin et al. 1988; Swanson and Dreyfuss 1988; GarciaBlanco et al. 1989). It should be noted, however, that the cross-linking ability and relative affinities of PTB/PBP for these sequences are intrinsic properties of this factor because identical results are obtained when the assays are performed using purified PTB/PBP instead of whole nuclear extract (data not shown).

\section{Discussion}

Role of the polypyrimidine tract in $3^{\prime}$ splice site selection

Splice site selection remains one of the outstanding problems in both constitutive and alternative pre- 
mRNA splicing. In the case of 3' splice site selection, the influence of the branchpoint sequence has recently been documented (Reed and Maniatis 1988; Zhuang et al. 1989). In contrast, although the pyrimidine tract has long been known to be an essential splicing element (Frendeway and Keller 1985; Reed and Maniatis 1985; Ruskin and Green 1985a) and has been implicated in determining $5^{\prime}$ splice site selection (Fu et al. 1988b), its role in $3^{\prime}$ splice site selection has been relatively unappreciated. Recently, it has been shown that the branchpoint sequence and the polypyrimidine tract are functionally linked (Smith et al. 1989b; Reed 1989) and that the 3' splice site itself is only specified relative to these elements by scanning for the first downstream AG (Smith et al. $1989 \mathrm{~b}$ ). Here, we provide convincing evidence for the involvement of both of these elements in splice site selection, with the polypyrimidine tract playing the predominant role.

The results presented here demonstrate clearly that default exon selection between $\alpha$ TM exons 2 and 3 is the result of competition between the branchpoint/polypyrimidine tract elements of exon 2 and 3 . The extensive pyrimidine tract of exon 3 and its consensus branchpoint outcompete the weaker elements associated with exon 2. The strength of the pyrimidine tract appears to be determined only by its length and pyrimidine content and by no additional sequence specificity, as demonstrated by the substitution of $\mathrm{P} 2$ with a generic pyrimidine tract (see Fig. 5). Selection of exon 3 is a genuine default choice, representing the outcome of competition between the constitutive splicing elements of exon 2 and 3 . No other specific elements are required for the exclusion of exon 2 by default. Comparison of the sequences of the quail (Lindquester et al. 1989) and chicken (M. Fiszman, pers. comm.). $\alpha \mathrm{TM}$ genes lends phylogenetic support to the biological significance of this competition, because the relative strengths of the $\mathrm{B} 2 \mathrm{P} 2$ and $\mathrm{B} 3 \mathrm{P} 3$ elements appear to be conserved in these two species.

\section{Splice site strength correlates with affinity for splicing factors}

The functional differences between the branchpoint/pyrimidine tracts probably reflect individual affinities for splicing factors involved early in spliceosome assembly. Consensus branchpoints are able to base-pair more efficiently with U2 snRNA (Wu and Manley 1989; Zhuang and Weiner 1989), consistent with their efficiency in cis competition assays (Reed and Maniatis 1988; Zhuang et al. 1989). A number of proteins have been identified that interact with the polypyrimidine tract /Gerke and Steitz 1986; Tazi et al. 1986; Ruskin et al. 1988; Swanson and Dreyfuss 1988; Garcia-Blanco et al. 1989). Of these, U2AF has been shown to be essential for splicing (Zamore and Green 1991) while fractions enriched in PTB/PBP are also required (J.G. Patton and B. NadalGinard, in prep.). Significantly, PTB/PBP binding to substrate RNAs containing branchpoint/pyrimidine tracts exactly parallels the performance of the same elements in cis competition, that is, $\mathrm{B} 3 \mathrm{P} 3>\mathrm{B} 2 \mathrm{P} 3>\mathrm{B} 3 \mathrm{P} 2>\mathrm{B} 2 \mathrm{P} 2$ (cf. Figs. 4, 5, and 7). As in the functional assays, the binding is more highly dependent on the po "vyrimidine tract, although the branchpoint sequence also has a definite effect. Whether this influence of the branchpoint on PTB/PBP binding is direct or whether it is mediated by other factors, such as U2 snRNP or U2AF, is not currently clear. However, $\mathrm{PTB} / \mathrm{PBP}$ shows the same pattern of binding when pure or in whole nuclear extract, suggesting a direct interaction. Evidence from studies in yeast also suggests that factors acting before U2 snRNP are also capable of recognizing the branchpoint sequence (Ruby and Abelson 1988; Sepharin and Rosbash 1989).

Binding of U2 snRNP to the branchpoint is dependent on U2AF (Ruskin et al. 1988). PTB/PBP binds to the polypyrimidine tract early in spliceosome assembly in an ATP-independent manner (Garcia-Blanco et al. 1989). Therefore, the preferential early interaction of U2AF and PTB/BPB with the branchpoint/polypyrimidine tract could account for the default selection of exon 3 by kinetic competition. Variations in the concentration of the constitutive splicing factor ASF/SF2 have been shown to modulate 5' splice site selection (Ge and Manley 1990; Krainer et al. 1990). Potentially, fluctuations between limiting and saturating levels of PTB/PBP, U2AF, or one of the other pyrimidine-binding proteins mentioned above could similarly affect $3^{\prime}$ splice site selection by amplifying or suppressing differences in their binding affinities to the branchpoint/pyrimidine tract elements. Such variations could give rise to significantly different cell-specific splicing patterns. Thus, default selection of aTM exons 2 and 3 appears to be simply the result of competition between splice sites with different affinities for common splicing factors. However, it does not involve specific "compatibilities" between particular pairs of splice sites as has been found for alternative splicing of the MLC1/3 gene (Gallego and Nadal-Ginard 1990).

\section{Comparison with other mutually exclusive exons}

A number of other systems have been used to analyze mutually exclusive exon selection, including chicken (Libri et al. 1989, 1990; Goux-Pelletan et al. 1990) and rat (Helfman et al. 1988,1990; Helfman and Ricci 1989) $\beta T M$ exons $6 \mathrm{~A}$ and $6 \mathrm{~B}$ (or 6 and 7 ), $\alpha$ TM exons 7 and 8 (D. Sengupta and B. Nadal-Ginard, unpubl.), and MLC1/3 exons 3 and 4 (Gallego and Nadal-Ginard 1990). There are some differences between $\alpha$ TM exons 2 and 3 and these other systems. However, there are also a number of underlying similarities. One difference is that in all of these other systems, mutually exclusive behavior is enforced by some mechanism other than proximity of the branchpoint to the $5^{\prime}$ splice site (Helfman and Ricci 1989; Gallego and Nadal-Ginard 1990; Goux-Pelletan et al. 1990; D. Sengupta and B. Nadal-Ginard, unpubl.). In addition, mutually exclusive splicing of rat $\beta$ TM exons 6 and 7 involves an ordered pathway in which splicing to the upstream constitutive exon 5 cannot occur until one of the mutually exclusive exons has been spliced to exon 8 (Helfman et al. 1988). Thus, selection between the $5^{\prime}$ 
splice sites of exons 6 and 7 determines exon selection. Such a requirement for presplicing to either exon 1 or 4 is not involved in default selection of $\alpha \mathrm{TM}$ exons 2 and 3 . Both the 1-3 and 1-2 splices occur efficiently in the absence of exon 4 (see Fig. 3). Similarly transcripts containing $\alpha$ TM exons 2-3-4 exhibit efficient splicing of 3-4 in vitro. Moreover, this pattern of splicing is not altered by constructing transcripts in which exon 2 has been prespliced to exon 1 (C. Smith, unpubl.).

Our results suggest that the splicing pattern of other pairs of mutually exclusive exons might be based on a similar competition between branchpoint/pyrimidine tract elements. Indeed, a number of alternatively spliced exons do have associated extensive polypyrimidine tracts (Emeson et al. 1989; Helfman and Ricci 1989; Libri et al. 1989; Goux-Pelletan et al. 1990; Helfman et al. 1990|. $\alpha$ TM exon 8 has an extensive polypyrimidine tract and is the default choice from a mutually exclusive exon pair (Wieczorek et al. 1988). In contrast, in the $\beta$ TMs, the downstream mutually exclusive exon $6 \mathrm{~B} / 7$, although having the more extensive polypyrimidine tract, is not the default choice, being selected only in muscle cells (Helfman et al. 1988; Libri et al. 1989). In these cases, however, additional cis elements within and flanking exon $6 \mathrm{~B} / 7$ prevent use of this exon in nonmuscle cells (Goux-Pelletan et al. 1990; Helfman et al. 1990; Libri et al. 1990). These elements appear to cause default suppression of exon 6B use by forming secondary structures (Libri et al. 1990). Mutations that remove the secondary structure allow competition between the exons that is determined by the branchpoint/polypyrimidine tract elements (M. Fiszman, pers. comm.). Thus, the underlying mechanism in these systems appears to be similar, with competition between polypyrimidine tract/branchpoint sequences determining exon selection, except when the competition is overridden by additional negative control. The polypyrimidine tract and its interaction with factors such as PTB/PBP, therefore, appear to have a general role in determining $3^{\prime}$ splice site selection that is likely to apply in both constitutive and alternatively spliced premRNAs.

\section{Switching from default to cell-specific splicing}

The results described above explain how the default splicing pattern of $\alpha$ TM exons 2 and 3 is established. An understanding of this process is essential to determine subsequently how the regulated smooth muscle-specific pattern is achieved. Theoretically, the switch from selection of exon 3 to the competitively weaker exon 2 could be accomplished by smooth muscle-specific splicing factors that act either by activating the exon 2 splice sites or by suppressing the splicing of exon 3 . The results reported here argue against the former scenario as the exon 2 splice sites can be used efficiently in the absence of cis competition by exon 3 (Figs. 2 and 3). Consistent with this, recent results (C. Smith et al., in prep.) indicate that regulation is achieved by inhibition of exon 3 . In smooth muscle cells, transcripts lacking exon 2 still splice out exon 3 . Thus, smooth muscle-specific selec- tion of exon 2 is due to withdrawal of exon 3 from competition. The skipping of exon 3 is dependent on negative regulatory sequences both flanking and within exon $3^{\prime}$ although unlike elements in the $\beta$ TM gene (Libri et al. 1990 ), these do not appear to depend on the formation of stem-loop structures. This negative regulation may be mechanistically similar to the examples of regulated splice site inhibition observed in Drosophila (Zachar et al. 1987; Sosnowskl et al. 1989; Siebel and Rio 1990).

The results described here underscore the important role of the polypyrimidine tract in determining splice site selection. Taken together, these observations further highlight the fact that in multi-intron transcripts the behavior of a particular splice site is not necessarily intrinsic to that site but can be determined, in a significant manner, by the other sites in the pre-mRNA. Splice sites that are usually bypassed can be efficiently selected upon modulation of competing sites. Changes in a single splice site can therefore have profound effects on the utilization of splice sites located at a great distance. Cellspecific trans-acting factors or limiting amounts of universal splicing factors with a wide range of affinities for different splice sites provide a mechanism in trans by which splice site selection can be modulated in a cellspecific manner.

\section{Materials and methods}

\section{Construct preparation}

Constructs were prepared by using standard cloning techniques (Maniatis et al. 1982). $\alpha$ TM clones were derived from the genomic clones $\lambda$ TM1 and $\lambda$ TM2 (Ruiz-Opazo and Nadal-Ginard $1987)$ and from the smooth and striated muscle $\alpha$ TM cDNAs (Ruiz-Opazo et al. 1985). TM exons 1-3 were subcloned as a 2.3-kb HindIII-EcoRI fragment; exon 4 was cloned as a 167-bp RsaI-Pst fragment, into a SmaI-PstI-digested polylinker. This exon 4 fragment was joined to exons $1-3$ by the polylinker EcoRI site, resulting in an effective $\sim 11.5$-kb intron deletion between exons 3 and 4 . In all of the constructs used for transfection, TM exon 1 was linked to the SV40 promoter at the NcoI site. Exon 4 was joined to downstream sequences either by the Ball site, which had been converted with HindIII linkers (all constructs in Fig. 1), or by the PstI site (all constructs in Fig. 6). The SV40 promoter/enhancer sequences and the 3 '-end sequence in pSV1-4SV were derived from pSV2Neo (Southern and Berg 1982). The $3^{\prime}$-end sequences in pSVUT and pSVSK were derived from the smooth and skeletal muscle-specific cDNA clones (Ruiz-Opazo and Nadal-Ginard 1987); in all other transfection constructs a poly(A) signal containing SV40 PstI-BamHI fragment was used. In constructs in which deletions of exons 2 and 3 and the flanking introns were made, the existing exons 2 and 3 were first deleted between the SacI sites at 349 and the polylinker site immediately downstream of EcoRI at 2229. Exon 2- and/or 3-containing fragments were reinserted using EcoRI linkers either into the SacI site at 349 (pT1-4, pT1-4C, pTS3D, pTA2A) or into the XhoI site at 261 (pTX2). The inserts for the constructs were pTl-4 SmaI(684)-PstI(1413), pTS3D SmaI(1011)-DraI(1791), pTA2A AccI(123)-AccI(1117), and pTX2 SmaI(684)-SmaI(1011). pT1-4C was derived from pT1-4 by inserting a half ScaI linker between the KpnI (1007) and SmaI (1011) sites, resulting in a precise sequence change from GUACCC to GUAAGU. 
For in vitro transcription the construct $\mathrm{pG} 4 \mathrm{X1}-4$ and derivatives were used. pG4X1-4 contained the NcoI(1)-EcoRI(2229) fragment containing exons $1-3$ attached at the $5^{\prime}$ end by a HindIII linker adjacent to the T7 promoter of pGEM4, and at the $3^{\prime}$ end to the EcoRI-PstI exon 4-containing fragment. Branchpoint and pyrimidine-substituted constructs were derived from pG4X1-4 through PCR-assisted cloning as follows. Substitutions of B2P2 were cloned between the $B g I I(806)$ and $X h o I(882)$ sites of intron 1; substitutions of B3P3 were made between the $K p n I(1007)$ and $P$ vulI $(1218)$ sites of intron 2. In pTM1 ${ }^{\mathrm{B3P}}{ }_{23}$, nucleotides 812-881 were replaced with nucleotides 10431220. In pTM12 $2^{\mathrm{B} 2 \mathrm{P} 2} 3$, nucleotides $1013-1220$ were replaced with nucleotides $776-881$ (B2P2). In $\mathrm{pTM}^{\mathrm{B} 2 \mathrm{P} 3} 23$, nucleotides 819-881 were replaced with nucleotides $1050-1220$. Construct pTM ${ }^{\mathrm{B} 3 \mathrm{P} 2} 23$ contains nucleotides $812-819$ replaced by nucleotides 1043-1049. Constructs pTM12 ${ }^{\mathrm{P} 39} 3$, pTM12 $2^{\mathrm{P} 17} 3$, pTM $12^{\mathrm{P} 9} 3$, and $\mathrm{pTM} 12^{\mathrm{P} 1} 3$ contained progressive deletions (nucleotides 1116-1089, 1116-1067,1116-1059, and 1116-1051, respectively) into the exon 3 polypyrimidine tract and were generated by cloning PCR-derived KpnI-AccI fragments with new AccI sites (GTATCT) introduced 39, 17, 9, and 1 residues after the branchpoint sequence. These fragments were recloned between the KpnI(1007) and $A c c I(1117)$ sites of pG4XI-4. pTM $1^{\text {Pgen }} 23$ was constructed by cloning a synthetic 70 -mer into $B g l l-X h o I$ sites of intron 1 . The sequence of this oligomer is as follows: 5'-GGCACTCTCCTCTCTTCCTTTTTTTCTTTTTTTGGCCGCCCGCGCCCCGTCTCCGTGTCCCAGCT-3'. It contains a pyrimidine tract of 35 nucleotides immediately $3^{\prime}$ of B2 adjacent to nucleotides 851-881 upstream of exon 2 .

The structures of all PCR-derived fragments were verified by sequencing.

\section{In vitro transcription and splicing reactions}

mRNA transcripts labeled with ${ }^{32} \mathrm{P}$ were transcribed from pGEM vectors with Pharmacia T7 or SP6 polymerase using a $\mathrm{G}\left(5^{\prime}\right) \mathrm{ppp}\left(5^{\prime}\right) \mathrm{G}$ dinucleotide primer as described (Konarska et al 1984). HeLa cell nuclear extracts were prepared according to the protocol of Dignam et al. (1983), following the modifications of Abmayr et al. (1988). Standard splicing reactions contained 50 fmoles of ${ }^{32} \mathrm{P}$-labeled pre-mRNA transcript, $3.2 \mathrm{mM} \mathrm{MgCl}_{2}, 500$ $\mu \mathrm{m}$ ATP, $20 \mathrm{~mm}$ creatine phosphate, $2.7 \%$ (wt/vol) polyvinyl alcohol, $1000 \mathrm{U} / \mathrm{ml}$ RNasin, $12.8 \mathrm{~mm}$ HEPES (pH 8), 14\%/vol/ vol) glycerol, $62 \mathrm{mM} \mathrm{KCl}, 0.12 \mathrm{~mm}$ EDTA, $1.7 \mathrm{~mm} \mathrm{DTT}$, and $60 \%$ nuclear extract. Reactions were carried out for indicated times at $30^{\circ} \mathrm{C}$ and subjected to proteinase $\mathrm{K}$ digestion and phenol/chloroform extraction. Splicing reaction intermediates were debranched in HeLa cell S-100 cytoplasmic fraction at $30^{\circ} \mathrm{C}$ for $30 \mathrm{~min}$ (Ruskin and Green 1985b). Reaction products were analyzed on $4 \%$ or $8 \%$ polyacrylamide denaturing gels containing $8 \mathrm{M}$ urea. Electrophoresis was performed in the presence of $1 \times$ TBE buffer.

\begin{abstract}
Lariat branchpoints were identified as follows: One pruole of ${ }^{32} \mathrm{P}$-end labeled oligonucleotides complementary to sequences within exon 2 (5'-TTTTGCTGAGATGTCCTC CTCGAG-3') or intron $2\left(5^{\prime}\right.$-CAGAGATGCTACGTCAGCTTCAG-3') were hybridized to 10-20 fmoles of spliced mRNA in $50 \%$ formamide, $400 \mathrm{~mm} \mathrm{NaCl}, 40 \mathrm{~mm}$ PIPES (pH 6.4), and $0.1 \mathrm{~mm}$ EDTA at $65^{\circ} \mathrm{C}$ for $15 \mathrm{~min}$ and then cooled to $30^{\circ} \mathrm{C}$ for $12 \mathrm{hr}$. After annealing, the reaction was ethanol-precipitated and resuspended in primer extension buffer $[50 \mathrm{~mm}$ Tris- $\mathrm{HCl}(\mathrm{pH} 8.3), 6 \mathrm{~mm}$ $\mathrm{MgCl}_{2}, 40 \mathrm{mM} \mathrm{KCl}$. Extension was performed In the presence of $2 \mathrm{mM}$ deoxynucleotide triphosphates and 10 units of AMV reverse transcriptase at $42^{\circ} \mathrm{C}$ for $20 \mathrm{~min}$. Radiolabeled RNA was degraded by treatment with $200 \mathrm{~mm} \mathrm{NaOH}$ for $1 \mathrm{hr}$ at room temperature, and the reactions were neutralized by the addition of $\mathrm{HCl}$. Products were analyzed on a $6 \%$ denaturing polyacrylamide gel alongside a sequencing reaction carried out on a double-stranded DNA template.
\end{abstract}

\section{Isolation and analysis of cellular RNA}

COS cells (Gluzman 1981) were grown in Dulbecco's modified Eagle medium supplemented with $10 \%$ fetal calf serum. Media and serum were obtained from GIBCO. DNA transfections were carried out by calcium phosphate coprecipitation followed by glycerol shock, as described previously (Breitbart and NadalGinard 1987).

Cytoplasmic RNA was isolated by a modification of the hot phenol method, as described previously (Breitbart and NadalGinard 1987; Wieczorek et al. 1988; Smith and Nadal-Ginard 1989).

End-labeled probes for S1 nuclease analysis were prepared from double-stranded DNA, as described previously (Smith and Nadal-Ginard 1989). Probes were 5 '-end-labeled by using $\left[\gamma^{-32} \mathrm{P}\right]$ ATP (Amersham) and T4 polynucleotide kinase (Bethesda Research Laboratories). Hybridization of RNA (5-25 mg) with probe $\left(0.5 \times 10^{5}\right.$ to $\left.1.0 \times 10^{5} \mathrm{cpm}\right)$ was in $25 \mu \mathrm{l}$ of $70 \%$ formamide, $400 \mathrm{~mm} \mathrm{NaCl}, 10 \mathrm{mM}$ PIPES, $0.5 \%$ SDS, and $1 \mathrm{mM}$ EDTA at $60^{\circ} \mathrm{C}$ overnight. Hybridized mixtures were digested for $1 \mathrm{hr}$ at $25^{\circ} \mathrm{C}$ with 100 units of S1 nuclease (Sigma, St. Louis, MO) in 300 $\mathrm{ml}$ of $200 \mathrm{~mm} \mathrm{NaCl}, 30 \mathrm{~mm}$ sodium acetate ( $\mathrm{pH} 4.5$ ), and $3 \mathrm{~mm}$ $\mathrm{ZnSO}_{4}$. After ethanol precipitation, fragments were separated by denaturing polyacrylamide gel electrophoresis and detected by autoradiography.

\section{UV cross-linking}

Binding reactions contained $40 \%$ nuclear extract, $2 \mathrm{mM} \mathrm{MgCl}_{2}$, $0.5 \mathrm{mM}$ DTT, 20 units of RNasin $1 \mathrm{ng}$ of labeled B3P3 RNA, and increasing amounts of unlabeled RNA. Binding was allowed to proceed for $30 \mathrm{~min}$ at $30^{\circ} \mathrm{C}$, after which reactions were placed at a distance of $7 \mathrm{~cm}$ from a 254-nm UV light and irradiated for 15 min. RNase A $(25 \mu \mathrm{g} / \mathrm{ml})$, micrococcal nuclease $(1000 \mathrm{U} / \mathrm{ml})$,

Table 1. Sequence of RNA cross-linking substrates

\begin{tabular}{ll}
\hline B3P3 & 5'-GGCTAACTTTCTCTTTCTCTCTCCCTCCCTGTCTTTCCCTCTCTCTCTCTTTCCCGC-3' \\
B2P3 & 5'-AGCCAACCTGGCACTTTCTCTTTCTCTCTCCCTCCCTGTCTTTCCCTCTCTCTCTCT-3' \\
B2P2 & 5'-AGCCAACCTGGCACCCGTTTGTTGTGTGTCTC-3' \\
B3P2 & 5'-GGCTAACCCGTTTGTTGTGTGTCTC-3' \\
GLB & 5'-CGCTGACTCTCTCTGCCTATTGGTCTATTTTCCCACCCTTAG-3' \\
17 & 5'-GGCTAACTTTCTCTTTCTCTCTCC-3' \\
9 & 5'-GGCTAACTTTCTCTTT-3' \\
\hline
\end{tabular}

Only the branchpoint and pyrimidine tract sequence elements are shown (for details, see Materials and methods). 
and $1 \mathrm{mM} \mathrm{CaCl}_{2}$ were added, and digestion was for $1 \mathrm{hr}$ at $37^{\circ} \mathrm{C}$. Laemmli sample buffer was then added, and samples were loaded onto 9\% Laemmli gels (Laemmli 1970). The various RNA substrates were all approximately the same size, and the relevant branchpoint/polypyrimidine tracts are shown in Table 1 with the branchpoint A enlarged.

\section{Acknowledgments}

We thank Emily Flynn McIntosh for assistance with the illustrations, Shahla Movahedi for oligonucleotide synthesis, Gurman S. Pall for assistance with experiments related to this work, and Roger Breitbart and Vijak Mahdavi for comments on the manuscript. This work has been supported in part by grants from National Institutes of Health and the Muscular Dystrophy Association of America.

The publication costs of this article were defrayed in part by payment of page charges. This article must therefore be hereby marked "advertisement" in accordance with 18 USC section 1734 solely to indicate this fact.

\section{References}

Abmayr, S.M., R. Reed, and T. Maniatis. 1988. Identification of a functional mammalian spliceosome containing unspliced pre-mRNA. Proc. Natl. Acad. Sci. 85: 7216-7220.

Breitbart, R.E. and B. Nadal-Ginard. 1987. Developmentally induced, muscle specific trans factors control the differential splicing of alternative and constitutive troponin- $T$ exons. Cell 41: 67-82.

Dignam, J.D., R.R. Lebovitz, and R.G. Roeder. 1983. Accurate transcription initiation by RNA polymerase II in a soluble extract from isolated mammalian nuclei. Nucleic Acids Res. 11: 1475-1489.

Emeson, R.B., F. Hediran, J.M. Yeakley, J.W. Guise, and M.G. Rosenfeld. 1989. Alternative production of calcitonin and CGRP mRNA is regulated at the calcitonin-specific splice acceptor. Nature 341: 76-80.

Eperon, L.P., J.P. Estibiero, and I.C. Eperon. 1986. The role of nucleotide sequences in splice site selection in eukaryotic pre-messenger RNA. Nature 324: 280-282.

Frendeway, D. and W. Keller. 1985. The stepwise assembly of a pre-mRNA splicing complex requires U-snRNPs and specific intron sequences. Cell 42: 355-367.

Fu, X-Y., J.D. Colgan, and J.L. Manley. 1988a. Multiple cis-acting sequence elements are required for efficient splicing of simian virus 40 small-t antigen pre-mRNA. Mol. Cell. Biol. 8: $3582-3590$.

- 1988. The role of the polypyrimidine stretch at the SV40 early pre-mRNA 3 ' splice site in alternative splicing. EMBO I. 7: 809-817.

Gallego, M.D. and B. Nadal-Ginard. 1990. Myosin light-chain $1 / 3$ gene alternative splicing: Cis regulation is based upon a hierarchical compatibility between splice sites. Mol. Cell. Biol. 10: 2133-2144.

Garcia-Blanco, M.A., S. Jamison, and P.A. Sharp. 1989. Identification and purification of a 62,000 dalton protein that binds specifically to the polypyrimidine tract of introns. Genes \& Dev. 3: 1874-1886.

Ge, H. and J.L. Manley. 1990. A protein factor, ASF, controls cell specific alternative splicing of SV40 early pre-mRNA in vitro. Cell 62: 25-34.

Gerke, V. and J.A. Steitz. 1986. A protein associated with small nuclear ribonucleoprotein particles recognizes the 3 ' splice site of premessenger RNA. Cell 47: 973-984.
Gluzman, Y. 1981. SV40 transformed simian cells support the replication of early SV40 mutants. Cell 23: 175-182.

Goux-Pelletan, M., D. Libri, Y. d'Aubenton-Carafa, M. Fiszman, E. Brody, and J. Marie. 1990. In vitro splicing of mutually exclusive exons from the chicken $\beta$ tropomyosin gene: Role of the branchpoint location and very long pyrimidine stretch. EMBO I. 9: 241-249.

Helfman, D., W.M. Ricci, and L.A. Finn. 1988. Alternative splicing of tropomyosin pre- mRNAs in vitro and in vivo. Genes \& Dev. 2: 16271638 .

Helfman, D. and W.M. Ricci. 1989. Branch point selection in alternative splicing of tropomyosin pre-mRNAs. Nucleic Acids Res. 17: 5633-5650.

Helfman, D. M., R.F. Roscigno, G.J. Mulligan, L.A. Finn, K.S. Wever. 1990. Identification of two distinct intron elements involved in alternative splicing of $\beta$-tropomyosin premRNA.

Genes \& Dev. 4: 98-110.

Konarska, M.M., R.A. Padgett, and P.A. Sharp. 1984. Recognition of cap structure in splicing in vitro of mRNA precursors. Cell 38: 731-736.

Krainer, A.R., G.C. Conway, and D. Kozak. 1990. The essential pre-mRNA splicing factor SF2 influences 5' splice site selection by activating proximal sites. Cell 62: 35-42.

Laemmli, U.K. 1970. Cleavage of structural proteins during the assembly of the head of bacteriophage T4. Nature 227: 680685.

Lees-Miller, J.P., L.O. Goodwin, and D.M. Helfman. 1990. Three novel brain tropomyosin isoforms are expressed from the rat $\alpha$-tropomyosin gene through the use of alternative promoters and alternative RNA processing. Mol. Cell Biol. 10: $1729-1742$.

Libri D., J. Marie, E. Brody, and M.Y. Fiszman. 1989. A subfragment of the $\beta$ tropomyosin gene is alternatively spliced when transfected into differentiating muscle cells. Nucleic Acids Res. 17: 6449-6463.

Libri D., M. Goux-Pelletan, E. Brody, and M. Fiszman. 1990. Exon as well as intron sequeneces are cis-regulating elements for the mutually exclusive alternative splicing of the $\beta$ tropomyosin gene. Mol. Cell. Biol. 10: 5036-5046.

Lindquester, G.J., J.E. Flachm, D.E. Fleenor, K.H. Hickman, and R.B. Devlin. 1989. Avian tropomyosin gene expression. $\mathrm{Nu}$ cleic Acids Res. 17: 2099-2119.

Maniatis, T., E.F. Fritsch, and J. Sambrook. 1982. Molecular cloning: A laboratory manual. Cold Spring Harbor Laboratory, Cold Spring Harbor, New York.

Mardon, H.J., G. Sebastio, and F.E. Baralle. 1987. A role for exon sequences in alternative splicing of the human fibronectin gene. Nucleic Acids Res. 15: 7725-7733.

Mayrand, S.H. and T. Pederson. 1990. Crosslinking of hnRNP proteins to pre-mRNA requires $U 1$ and $U 2$ snRNPs. Nucleic Acids. Res. 18: 3307-3318.

McKeown, M. 1991. Genetic engineering, principles and practice. (in press).

Mount, S.M. 1982. A catalogue of splice junction sequences. Nucleic Acids Res. 10: 459-472.

Ohshima, Y. and Y. Gotoh. 1987. Signals for the selection of a splice site in pre-mRNA. J. Mol. Biol. 195: 247-259.

Parker, R., P.G. Siliciano, and C. Guthrie. 1987. Recognition of the TACTAAC box during mRNA splicing in yeast involves base pairing to the U2-like snRNA. Cell 49: 229- 239.

Reed, R. 1989. The organization of $3^{\prime}$ splice-site sequences in mammalian introns. Genes \& Dev. 3: 2113-2123.

. 1988. The role of the mammalian branchpoint sequence in pre-mRNA splicing. Genes \& Dev. 2: 1268-1276.

Reed, R. and T. Maniatis. 1985. Intron sequences involved in 
lariat formation during pre-mRNA splicing. Cell 41: 95-105

1986. A role for exon sequences and splice-site proximity in splice-site selection. Cell 46: 681-690.

Ruby, S.W. and J. Abelson. 1988. An early hiearchic role of U1 small nuclear ribonucleoprotein in spliceosome assembly. Science 242: 1028-1035.

Ruiz-Opazo, N., J. Weinberger, and B, Nadal-Ginard. 1985. Comparison of $13 \alpha$-tropomyosin sequences from smooth and striated muscle. Nature 315: 67-70.

Ruiz-Opazo, N. and B. Nadal-Ginard. 1987. $\alpha$-Tropomyosin gene organization. J. Biol. Chem. 261: 4755-4765.

Ruskin, B. and M.R. Green. 1985. Role of the $3^{\prime}$ splice site consensus sequence in mammalian pre-mRNA splicing. $\mathrm{Na}$ ture 317: 732-734.

1985b. An RNA processing activity that debranches RNA lariats. Science 229: 135-140.

Ruskin, B., P.D. Zamore, and M.R. Green. 1988. A factor, U2AF, is required for U2 snRNP binding and splicing complex assembly. Cell 52: 207-219.

Seraphin, B. and M. Rosbash. 1989. Identification of functional U1 snRNA-pre-mRNA complexes committed to spliceosome assembly and splicing. Cell 59: 349-358.

Siebel, C.W. and D.C. Rio. 1990. Regulated splicing of the Drosophila P transposable element third intron in vitro: Somatic repression. Science 248: 1200-1208.

Smith, C.W.J. and B. Nadal-Ginard. 1989. Mutually exclusive splicing of $\alpha$-tropomyosin exons enforced by an unusual lariat branch point location; Implications for constitutive splicing. Cell 56: 749-758.

Smith, C.W.J., J.G. Patton, and B. Nadal-Ginard. 1989a. Alternative splicing in the control of gene expression. Annu. Rev. Genet. 23: $527-577$.

Smith, C.W.J., E. Porro, J.G. Patton, and B. Nadal-Ginard. 1989b. Scanning from an independently specified branchpoint defines the $3^{\prime}$ splice site of mammalian introns. Nature 342: 243-247.

Solnick, D. 1985. Alternative splicing caused by RNA secondary structure. Cell 43: 667-676.

Sosnowski, B., J.M. Belote, and M. McKeon. 1989. Sex-specific alternative splicing of RNA from the transformer gene results from sequence-dependent splice site blockage. Cell 58: $449-459$.

Streuli, M. and H. Saito. 1989. Regulation of tissue-specific alternative splicing: Exon-specific cis-elements govern the splicing of leukocyte common antigen pre-mRNA. EMBO J. 8: 787-796.

Southern, P.J. and P. Berg. 1982. Transformation of mammalian cells to antibiotic resistance with a bacterial gene under control of the SV40 early region promoter. I. Mol. Appl. Genet. 1: $327-341$.

Swanson, M.S. and G. Dreyfuss. 1988. RNA binding specificity of hnRNP proteins: A subset bind to the 3 ' end of introns. EMBO I. 7: 3519-3529.

Tazi, J., C. Alibert, J. Temsamani, I. Reveillaud, G. Cathala, C. Brunel, and P. Jeanteur. 1986. A protein that specifically recognizes the 3' splice site of mammalian pre-mRNA introns is associated with a small nuclear ribonucleoprotein. Cell 47: 755-766.

Treisman, R., S.H. Orkin, T. Maniatis. 1983. Specific transcription and RNA splicing defects in five cloned $\beta$-thalassemia genes. Nature 302: 591-96.

Wieczorek, D., C.W.J. Smith, and B. Nadal-Ginard. 1988. The rat $\alpha$-tropomyosin gene generates a minimum of six different mRNAs coding for striated, smooth and non-muscle isoforms by alternative splicing. Mol. Cell Biol. 8: 679-694.
Wu, J. and J.L. Manley. 1989. Mammalian pre-mRNA branch site selection by U2 snRNP involves base pairing. Genes \& Dev. 3: 1553-1561.

Zachar, A., T-B. Chou, and P.M. Bingham. 1987. Evidence that a regulatory gene autoregulates splicing of its transcript. EMBO I. 6: 4105-4111.

Zamore, P.D. and M.R. Green. 1990a. Identification, purification, and biochemical characterization of U2 small nuclear ribonucleoprotein auxiliary factor. Proc. Natl. Acad. Sci. 86: 9243-9247.

Zamore, P.D. and M.R. Green. 1991. Biochemical characterization of U2 snRNP auxiliary factor: An essential pre-mRNA splicing factor with a novel intranuclear distribution. EMBO I. 10: 207-214.

Zhuang, Y., and A.M. Weiner. 1986. A compensatory base change in U1 snRNA suppresses a $5^{\prime}$ splice site mutation. Cell 46: 827-835

Zhuang, Y., H. Leung, and A.M. Weiner. 1987. The natural 5' splice site of simian virus 40 large $\mathrm{T}$ antigen can be improved by increasing the base complementarity to U1 RNA. Mol. Cell. Biol. 7: 3018-3020

Zhuang, Y. and A.M. Weiner. 1989. A compensatory base change in human U2 snRNA can suppress a branch site mutation. Genes \& Dev. 3: 1545-1552.

Zhuang, Y., A.M. Goldstein, and A.M. Weiner. 1989. UACUAAC is the preferred branch site for mammalian mRNA splicing. Proc. Natl. Acad. Sci. 86: 2752-2756. 


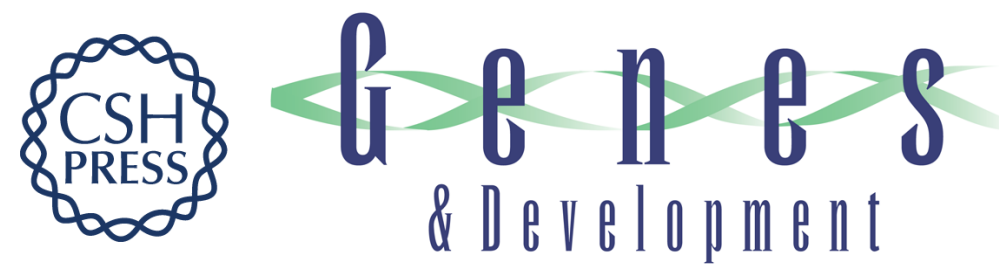

\section{Alpha-tropomyosin mutually exclusive exon selection: competition between branchpoint/polypyrimidine tracts determines default exon choice.}

M P Mullen, C W Smith, J G Patton, et al.

Genes Dev. 1991, 5:

Access the most recent version at doi:10.1101/gad.5.4.642

References This article cites 60 articles, 18 of which can be accessed free at: http://genesdev.cshlp.org/content/5/4/642.full.html\#ref-list-1

License

Email Alerting Service

Receive free email alerts when new articles cite this article - sign up in the box at the top right corner of the article or click here.

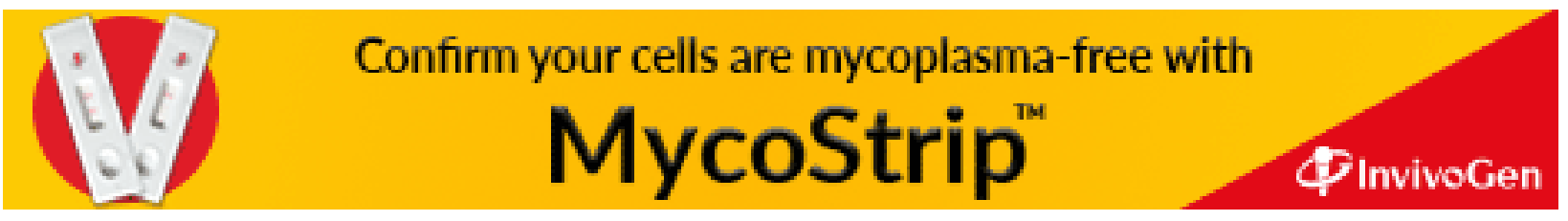

